\title{
Aplikasi Pembelajaran Mata Kuliah Aransemen Musik Pendidikan II: Studi Kasus di SMP Al-Azhar Yogyakarta
}

\author{
Ayu Tresna Yunita \\ Dosen Jurusan Musik, FSP ISI Yogyakarta \\ Telp. 08164260869; e-mail: ayutresnayunita@yahoo.com
}

\begin{abstract}
The two music subjects, the Educational Music Arrangement I and II of the Musical Arts study program's 2009 curriculum, which was grouped in the work skills section course works of the curriculum. At the same time, the two subjects are also the part of Educational Music main interest package, which is one of the five elective packages offered by the program. Course description of the Arrangement Education II states that its course participants should be capable to compose an educational ensemble music arrangement for junior secondary schools. This research will contribute to overcoming some obstacles as well as to find solutions in the teaching process of Educational Music Arrangement in the form of school music ensemble. This study is processed through descriptive qualitative approach analysis using the theoretical method. The mastery of musical elements as the basis arrangements making in which subjects is related to musical concepts such as shape, harmony, counterpoint, and composition as the tools. In this study, the results of musical arrangement theory were obtained during the lecture Educational Music Arrangement II, was then applied to the SMP Al-Azhar Yogyakarta, then the results were deeply then examined. The results of musical education arrangement course can be applied in music teaching at the SMP Al-Azhar. This study concludes that new instrumental ensemble arrangement which utilizes several recorders, the pianica, violin, glockenspiel, percussion, electric guitar, electric bass, keyboards, and vocals drums set is appropriate for the practice of musical ensemble music for Junior High School level.
\end{abstract}

Keywords: educational music; arrangement; ensemble

\begin{abstract}
Abstrak
Mata Kuliah Aransemen Musik Pendidikan I dan II pada kurikulum 2009 Program Studi Seni Musik, termasuk kelompok mata kuliah keahlian berkarya yang terdapat didalam minat utama Musik Pendidikan. Deskripsi mata Kuliah Aransemen Musik Pendidikan II yaitu mampu membuat aransemen musik pendidikan dengan bentuk ansambel musik untuk tahap menengah (siswa Sekolah Menengah Pertama). Penelitian ini berguna untuk mengatasi kendala dan mencari solusi pada proses pengajaran Aransmemen Musik Pendidikan dalam bentuk ansambel musik di sekolah Penelitian ini adalah penelitian deskriptif analisis menggunakan metode penelitian kualitatif dengan pendekatan metode teoritical. Penguasaan materi unsur-unsur musik menjadi dasar untuk membuat aransemen di mana subyek terkait dengan konsep-konsep seperti bentuk, harmoni, tandingan, dan perangkat komposisi (Watanabe;1967,5). Pada penelitian ini, hasil teori tentang aransemen musik yang didapat selama proses perkuliahan aransemen musik pendidikan II di kelas, selanjutnya diaplikasikan ke SMP Al Azhar Yogyakarta yang kemudian hasilnya lalu dikaji lebih mendalam. Hasil aransemen mata kuliah aransemen musik pendidikan dapat di aplikasikan di SMP Al-Azhar. Bentuk aransemen dengan format ansambel yang menggunakan instrumen rekorder, pianika, biola, glokenspiel, perkusi, gitar elektrik, bass elektrik, keyboard, drumset serta vokal menjadi ansambel musik bentuk baru yang memang tepat bagi kegiatan ansambel musik di Sekolah Menengah Pertama.
\end{abstract}

Kata kunci : musik pendidikan; aransemen; ensambel

\section{Pengantar}

Program Studi Musik Pendidikan merupakan pengembangan dari kurikulum
Sarjana Seni, yang secara historis telah ada sejak Akademi Musik Indonesia (AMI) dan pada awalnya disebut dengan Program Studi 
Musik Sekolah. Pada perkembangannya Program Studi Musik Sekolah berubah menjadi Minat Utama Musik Pendidikan. Profil lulusan program studi ini antara lain adalah menjadi Aranger dan Tutor/ pelatih ketrampilan instrumen/ vokal. Mata Kuliah Aransemen Musik Pendidikan I dan II pada kurikulum 2009 Program Studi Seni Musik, termasuk kelompok mata kuliah keahlian berkarya yang terdapat didalam minat utama Musik Pendidikan. Berdasarkan data tersebut, kedudukan mata kuliah Aransemen Musik Pendidikan menjadi kompetensi utama untuk menghasilkan lulusan mahasiswa minat utama Musik Pendidikan yang berkompeten dibidangnya.

Deskripsi Mata Kuliah Aransemen Pendidikan I yaitu mampu membuat aransemen musik pendidikan dengan bentuk ansambel musik untuk tahap awal atau pemula (siswa Sekolah Dasar), dan deskripsi mata Kuliah Aransemen Musik Pendidikan II yaitu mampu membuat aransemen musik pendidikan dengan bentuk ansambel musik untuk tahap menengah (siswa Sekolah Menengah Pertama).

Instrumen yang digunakan adalah instrumen Recorder, Pianika, Glokenspiel, Gitar, Keyboard, dan alat-alat ritmis seperti Castanet, Tamborin, Triangle, Snar Drum dan alat-alat ritmis lainnya. Instrumen yang digunakan pada Aransemen Musik Pendidikan II dtambah dengan instrumen Keyboard, Gitar Elektrik, Bass Gitar elektrik dan Drum Set. Hasil aransemen yang sudah sesuai dengan Silabus dan Satuan Ajaran Perkuliahan Arasemen Musik Pendidikan selanjutnya dipraktekkan langsung kepada siswasiswa sekolah pada tahap awal maupun siswa tahap menengah dalam format ansambel musik anak. Kegiatan bermain musik dapat memberikan kontribusi dan membantu anak bersosialisasi dengan teman sebaya untuk memainkan musik secara bersama atau berkelompok (Hurlock, 1991: 331). Mata pelajaran Kesenian (seni musik) termasuk salah satu mata pelajaran seni budaya yang terdapat dalam kurikulum untuk Sekolah Menengah Pertama. Secara umum pengajaran seni musik di sekolah Menengah Pertama tidak bisa berjalan maksimal karena kurangnya pengetahuan dan pemahaman para pendidik. Minimnya pengetahuan dan pemahaman para para pendidik tentang pembelajaran seni musik secara ansambel menyebabkan musikalitas para siswa kurang berkembang. Berdasarkan hal inilah yang mendorong agar diadakan kegiatan pembelajaran ansambel di sekolah dengan pengetahuan teori aransemen musik pendidikan sehingga proses pengajaran ansambel musik pendidikan dapat dilakukan dengan tepat dan terarah. Pelaku pengajaran ansambel adalah mahasiswa yang mengambil mata kuliah Aransmen Musik Pendidikan II serta melibatkan guru kesenian di sekolah.

Tujuan dari penerapan hasil pembelajaran aransemen musik pendidikan pada pembelajaran ansambel musik di sekolah agar mahasiswa dan para pendidik mendapatkan pengetahuan dan pemahaman tentang bentuk aransemen musik dan dapat mengajarkan kepada siswa dalam bentuk ansambel musik. Di samping itu juga untuk memberikan apresiasi seni khususnya seni musik dan meningkatkan kemampuan ketrampilan bermain instrumen musik.

Manfaat bagi mahasiswa yang mengambil mata kuliah aransemen musik pendidikan antara lain mampu membuat aransemen musik dalam bentuk ansambel musik untuk siswa Sekolah Menengah Pertama dengan instrumen-intstrumen yang sudah ditentukan, mampu melatih dan mengaplikasikan hasil aransemen secara langsung kepada siswa-siswa di sekolah, serta mempunyai pengalaman mengajar se-cara langsung kepada siswa-siswa disekolah. Hal tersebut sesuai dengan profil lulusan program studi Musik Pendidikan antara lain adalah menjadi aranger dan Tutor/ pelatih keterampilan instrumen/ vokal dan ansambel musik. 
Penelitian tentang Aplikasi Pembelajaran Mata Kuliah Aransemen Musik Pendidikan II, studi kasus di SMP Al-Azhar Yogyakarta belum pernah dilakukan. Pada penelitian terdahulu terdapat beberapa penelitian dengan objek Aransemen Musik Anak, yang meneliti tentang peranan aransemen, bentuk-bentuk aransemen, model pembelajaran Ansambel. Perbedaan pada penelitian ini yaitu meneliti bagaimana bentuk aransemen musik yang tepat bagi siswa Sekolah Pertama dan untuk mengetahui apakah hasil aransemen musik tersebut dapat diterapkan ke siswa Sekolah Pertama.

Hasil dari penelitian ini untuk mengetahui bentuk aransemen musik pendidikan yang sesuai dengan kemampuan siswa Sekolah Menengah Pertama dan menjadi masukan ilmu pengetahuan sehingga hasil dari kuliah Aransemen Musik Pendidikan akan selalu berkembang ke arah yang lebih baik. Penelitian ini berguna untuk mengatasi kendala dan mencari solusi pada proses pengajaran Aransmemen Musik Pendidikan dalam bentuk ansambel musik di sekolah.

Masalah yang diangkat dalam penelitian ini terrumuskan sebagai berikut: (1) Bagai-manakah cara membuat aransemen musik pendidikan yang tepat bagi siswa Sekolah Menengah Pertama? (2) Apakah hasil aran-semen musik pendidikan dapat diapli-kasikan pada proses pengajaran ansambel musik di SMP Al-Azhar Yogyakarta?

\section{Pembahasan}

\section{Penelitian/ Penciptaan Terdahulu}

Terdapat beberapa penelitian yang telah dilakukan dengan objek Aransemen Musik Anak dan Ansambel Musik Anak. Penelitian tersebut antara lain "Peranan Aransemen Musik Anak Sebagai Materi Perkuliahan Jurusan Musik FSP ISI Yogyakarta dan Media komunikasi" oleh Yc. Budi Santosa, tahun 2010. Penelitian ini berisi tentang aransemen musik anak sebagai materi per- kuliahan yang mencakup penjelasan tentang pengertian, ciri khas dan prinsip aransemen musik anak. Kemudian menguraikan tentang struktur dasar aransemen, langkahlangkah menyusun aransemen, berbagai macam pengolahan aransemen dan aransemen musik anak sebagai media komunikasi.

Penelitian berikutnya yaitu, "Model Pembelajaran Seni Musik dalam bentuk Ansambel untuk Siswa Sekolah Lanjutan Tingkat Pertama" oleh R. Taryadi, Tri Wahyu Widodo, Bambang Riyadi pada tahun 2009. Penelitian ini meneliti tentang manfaat dan tujuan pembelajaran ansambel musik, ansambel musik untuk pembelajaran seni musik, perpektif musik untuk pendidikan, model pembelajaran seni musik dalam bentuk ansambel dan model pembelajaran repertoar ansambel musik

Dari penelitian yang telah dilakukan terdahulu tidak ada penelitian tentang hasil penerapan aransemen musik pendidikan ke dalam proses pengajaran ansambel musik di sekolah, dan tidak ada penelitian tentang kendala yang dihadapi pada saat proses pengajaran ansambel musik dan solusi besrta pemecahan masalah.

Grant Newman, Teaching Children Music, Fundamental of Music and Methode (USA: Wim C. Brown Publisher, 1979). Buku ini membahas tentang bagaimana menga-jarkan musik bagi anak, mengenalkan unsurunsur musik seperti ritmis, melodi dan harmoni yang sesuai bagi anak, men-dengarkan musik, bernyanyi dan memain-kan instrumen musik. Buku ini menjadi dasar dalam proses penyusunan aransemen sehingga dapat mengaransemen musik yang tepat bagi anak.

Genichi Kawakami, Arranging Popular Music: A Practical Guide, (Tokyo: Yamaha Music Foundation, 1975). Pada buku ini Genichi Kawakami menjelaskan pengertian dasar seperti penyusunan akord (harmoni), tentang rhythm, bagaimana membuat frase/melodi, hingga analisa yang bersifat struktural. Buku ini menjadi acuan untuk 
melakukan aransemen secara sistematis sehingga membantu dalam proses pengerjaan aransemen.

Leon Stein, Structure and Style: The Study and Analysis of Musical Form, Expand Edition (New Jersey, USA: Summy-Birchard Music, 1979). Buku ini menguraikan definisi figure, motif, frase, tema dalam analisis struktural dari karya musik. Analisis merupakan salah satu unsur penting dalam proses aransemen. Dalam buku ini dibahas tentang proses analisis struktur musik. Analisis struktur musik harus dipahami dalam proses pembuatan aransemen musik, mengetahui bentuk struktur musik, mengetahui motif, serta frase yang terdapat pada hasil aransemen, sehingga dapat membantu aranger dalam penyusunan aransemen

Hasil dari penelitian ini diharapkan dapat berguna untuk menambah dan melengkapi hasil dari penelitian yang sudah ada, dan berguna bagi perkem-bangan ilmu pengetahuan dalam bidang musik.

\section{Landasan Teori}

Untuk dapat membuat aransemen musik pendidikan yang dapat diaplikasikan ke Sekolah Menengah Pertama Al Azhar Yogyakarta menggunakan landasan teori musikologi. Pembuatan aransemen musik memerlukan teori aransemen musik. Unsurunsur musikal melodi, ritme dan harmoni adalah hal penting dalam pembuatan aransemen. Unsur musikal merupakan dasar mengaransemen musik dalam bentuk ansambel musik. Melodi merupakan rangkaian nada-nada yang terstruktur secara ritmis dan dan berirama (Scholes, 1964: 362).

Dalam rangkaian nada-nada tersebut terdapat pergerakan nada-nada dengan gerakan naik, turun maupun tetap. Pemilihan lagu atau melodi dipilih yang sesuai dengan pola bentuk sekuen, jarak nada atau interval pada melodi dalam gerakan melangkah dan melompat dalam wilayah nada yang terjangkau. Lagu yang dipilih adalah lagu yang sederhana, mudah dihafal dan dinyanyikan.

Pola-pola ritme yang digunakan merupakan pola ritme yang berulang dengan penambahan variasi. Ritme dipertimbangkan sebagai komponen waktu yang memberikan pernyataan hidup kepada musik dan dihasilkan dari unsur aksentuasi dan durasi (Miller, 1971: 18). Harmoni dalam musik adalah salah satu teori musik tentang penyusunan suatu rangkaian nada-nada dalam akords. Harmoni adalah elemen musik yang mempengaruhi melodi (Miller, 1971: 18). Dengan mengetahui susunan akord-akord harmoni dalam lagu, dapat dibuat aransemen dengan bentuk melodi yang berbeda, membuat melodi untuk instrumen-instrumen musik yang sesuai dengan harmoni lagu.

Berdasarkan masalah yang telah dirumuskan maka tujuan dari penelitian adalah: (1) Mengetahui tahapan-tahapan pembuatan Aransemen Musik Pendidikan II, (2) Mengetahui apakah hasil aransemen tersebut dapat diterapkan di Sekolah Menengah Pertama. Penelitian ini berguna untuk perkembangan ilmu pengetahuan khususnya seni musik tentang aransemen musik pendidikan yang sesuai dengan kemampuan siswa Sekolah Menengah Pertama, sehingga mata kuliah Aransemen Musik Pendidikan akan selalu berkembang ke arah yang lebih baik sesuai dengan perkembangan jaman.

Manfaat penelitian selanjutnya adalah untuk menambah wawasan dan apresiasi seni khususnya seni musik kepada mahasiswa, kepada siswa sekolah menengah pertama dengan bermain musik bersama atau ansambel, memberikan wawasan pengetahuan seni kepada para pendidik atau guru di sekolah-sekolah dan orangtua siswasiswa sekolah serta masya-rakat luas. Kontribusi Penelitian ini jaga menambah khasanah perkembangan ilmu pengetahuan seni khususnya seni musik. 


\section{Metode Penelitian}

Penelitian ini adalah penelitian deskriptif analisis menggunakan metode penelitian kualitatif dengan pendekatan metode teoritical. Penguasaan materi unsurunsur musik menjadi dasar untuk membuat aransemen di mana subyek terkait dengan konsep-konsep seperti bentuk, harmoni, tandingan, dan perangkat komposisi (Watanabe, 1967: 5). Pada penelitian ini, hasil teori tentang aransemen musik yang didapat selama proses perkuliahan aransemen musik pendidikan II di kelas, selanjutnya diaplikasikan ke SMP Al Azhar Yogyakarta yang kemudian hasilnya lalu dikaji lebih mendalam.

Penelitian kualitatif menurut Bogdan dan Taylor yaitu untuk meng-hasilkan data deskriptif berupa kata-kata tertulis atau lisan dari orang-orang dan perilaku yang dapat diamati. Penelitian kualitatif untuk memahami fenomena tentang apa yang dialami oleh objek penelitan misalnya perilaku, persepsi, motivasi, tindakan dan lain-lain secara holistik dengan cara deskripsi dalam bentuk kata-kata dan bahasa, pada konteks khusus yang alamiah dan dengan memanfaatkan berbagai metode alamiah. Dalam penelitian kualitatif metode yang biasanya dimanfaatkan adalah wawancara, pengamatan, dan pemanfaatan dokumen (Moleong, 2010: 6).

Penelitian ini dilaksanakan dalam tiga tahap yaitu pengumpulan data, tahap pelaksanaan, dan tahap penulisan laporan. Pengumpulan data dilakukan melalui studi pustaka, observasi, dan dokumentasi. Studi Pustaka dilaksanakan dengan mencari dan mempelajari referensi berupa buku-buku, makalah, artikel dan berbagai sumber catatan yang berhubungan dengan permasalahan. Data tentang pembuatan aransemen diperoleh dari buku-buku koleksi pribadi dan buku-buku yang terdapat di perpustakaan ISI Yogyakarta.

Observasi dilaksanakan dengan pengumpulan data yang dilakukan melalui pengamatan dengan disertai pencatatanpencatatan terhadap keadaan atau perilaku objek sasaran. Pengumpulan data juga dilakukan dengan wawancara. Wawancara adalah percakapan dengan maksud tertentu yang dilakukan oleh dua pihak, yaitu pewawancara (interviewer) yang mengajukan pertanyaan dan terwawancara (interviewee) yang memeberikan jawaban atas pertanyaan tersebut (Moleong, 2010: 186).

Observasi yang dilakukan pada penelitian ini dimulai sejak awal perkuliahan aransemen musik pendidikan II berlangsung, yaitu pada sememster genap tahun ajaran 2014-2015. Observasi selanjutnya dilakukan di Sekolah SMP Al Azhar Yogyakarta pada saat mahasiswa mulai melakukan proses pengajaran ansambel musik di sekolah dimulai pada bulan April 2015, Wawancara dilakukan untuk memengkapi data pada penelitian ini. Wawancara dengan guru pegampu ekstrakurikuler musik dan siswa di sekolah dilakukan untuk memperoleh data yang akurat.

Dokumentasi dilaksanakan untuk mengumpulkan data hasil peng-amatan maupun pencatatan maka diperlukan suatu bentuk pendokumentasian untuk memperkuat suatu data atau tulisan. Dokumentasi berupa foto dan video selama proses pengajaran hasil ansambel hingga pada saat hasil pengajaran ansambel dipentaskan pada acara Akhirusanah SMP Al Azhar Yogyakarta di Aunditorium MMTC pada bulan Juni 2015 diperlukan untuk melengkapi data penelitian.

Dua tahap berikutnya ialah tahap pelaksanaan, yaitu data yang telah terkumpul kemudian diurutkan untuk dideskripsikan dan dianalisis, dan yang terakhir ialah tahap Penyusunan Laporan, yaitu data-data yang diperoleh dirangkum, diananalisis, dan kemudian ditulis ke dalam sebuah bentuk penulisan karya tulis. 


\section{Aransemen Musik Pendidikan Bagi Siswa Sekolah Pertama}

Sekolah yang dipilih untuk meng-aplikasikan hasil aransemen mata kuliah Aransemen Musik Pendidikan II adalah SMP Al-Azhar Yogyakarta. Sekolah SMP AlAzhar sudah menjadi tempat untuk pengajaran hasil aransemen sejak tahun 2014, yang diadakan pada setiap tahun ajaran semester genap. Pengajaran musik di Sekolah SMP AlAzhar merupakan kegiatan ekstrakurikuler yang dibimbing oleh Bapak Tri Untoro, S.Pd. Kegiatan ekstrakurikuler musik dilaksanakan tiap hari kamis, seminggu 1 kali pertemuan dengan durasi 60 menit. Kegiatan ini diikuti oleh kurang lebih 25 orang siswa, terdiri dari siswa kelas VII hingga kelas IX. Instrumen yang digunakan antara lain gitar elektrik, bass elektrik, drumset, dan vokal.

Format ekstrakurikuler musik yang berjalan selama ini adalah format band dengan 5 orang pemain yaitu pemain gitar elektrik, bass elektrik, keyboard, drumset dan penyanyi. Format band merupakan format yang paling mudah dilaksanakan di kegiatan ekstrakurikuler musik SMP Al-Azhar, karena jika ingin merubah format band misalnya menjadi format ansambel musik dengan penambahan alat-alat berupa rekorder, pianika, perkusi dan biola, para guru kesulitan dalam masalah aransemen lagu yang akan dimainkan. Untuk mengatasi kesulitan tersebut, hasil penelitian ini dapat menjadi salah satu solusi dalam hal mengatasi keterbatasan aransemen dengan format ansambel musik.

Format musik dengan bentuk ansambel musik yang terdiri dari instrumen rekorder, pianika, perkusi, biola, gitar elektrik, basaa elektrik, keyboard dan vokal menjadi bentuk baru bagi kegiatan musik di SMP AlAzhar Yogyakarta. Guru pengampu ekstrakurikuler musik mendapat wawasan dan tambahan pengetahuan tentang aransemen musik format ansambel, para siswa juga mendapat pengatahuan, wawasan dan pengalaman baru pada saat megikuti kegiatan ansambel musik di sekolah.
Lagu yang dipilih untuk diaransemen adalah lagu-lagu daerah atau lagu-lagu nasional. Lagu yang dipilih utuk diaran-semen pada saat ini adalah lagu "Dari Sabang sampai Merauke". Lagu tersebut merupakan salah satu lagu nasional yang dipilih untuk di aransemen dengan tujuan supaya dapat meningkatkan rasa kebangsaan dan kecintaan terhadap tanah air Indonesia. Lagu "Dari Sabang Sampai Merauke" mempunyai ritme musik yang semangat sehingga lagu ini dianggap tepat dimainkan oleh siswa-siswa di sekolah SMP Al Azhar Yogyakarta. Lagu "Dari Sabang Sampai Merauke" diaransemen untuk instrumen rekorder, pianika, biola, glokenspiel, perkusi, gitar elektrik, bass elektrik, keyboard, drumset dan vokal. Bentuk aransemennya terdiri dari intro, lagu, interlude, lagu dan koda.

Aransmen lagu "Dari Sabang Sampai Merauke" dibuat dalam tangganada G mayor. Aransemen pada instrumen rekorder hanya menggunakan wilayah nada satu oktaf yaitu dari nada $\mathrm{C}$ sampai $\mathrm{C} 1$. Aranse-men untuk instrumen pianika menggunakan wilayah nada tiga oktaf yaitu nada $C$ sampai E3. Aransemen instrumen glokenspiel dibuat sebagai melodi isian atau filler, sehingga pada beberapa birama melodi instrumen glokenspiel terdengar lebih menonjol. Hal ini menjadikan aransemen menjadi lebih menarik dan menjadi tantangan bagi pemain glokenspiel untuk bisa menguasai teknik ketrampilan permainan. Teknik ketrampilan yang digunakan dalam intrumen perkusi dan drumset diaransmen dengan menggunakan pola-pola ritmis yang dinamik dengan penambahan ritmis-ritmis sinkope untuk menambah krativitas para siswa.

Aransemen untuk instrumen comba band seperti gitar elektrik, bass gitar, keyboard masih menggunakan akor-akor pokok. Aransmen untuk vokal diaransmen dalam satu suara. Pembatasan wilayah nada dan penggunaan akord untuk instrumen bertujuan untuk mempermudah anak agar mampu memainkan hasil aransemen tanpa 
merasa kesulitan pada teknik permainannya.

\section{Aplikasi Hasil Aransemen Musik Pendi- dikan pada Proses Pengajaran Ansambel Musik di SMP Al-Azhar Yogyakarta}

Proses penganjaran hasil aransemen mata kuliah aransemen musik pendidikan di SMP Al Azhar dilaksanakan sebanyak enam kali pertemuan. Pertemuan dilakukan seminggu satu kali setiap hari kamis jam 13;3014.30 wib. Tempat latihan ansambel musik memakai ruang ansambel musik. Instrumen yang sudah dimiliki SMP Al-Azhar adalah instrumen gitar elektrik, bass elektrik, keyboard dan drumset. Instrumen lainnya seperti rekorder, pianika dan biola adalah instrumen pribadi yang sudah banyak dimiliki oleh sisiwa-siswa sekolah SMP Al Azhar.

Setelah aransemen lagu "Dari Sabang Sampai Merauke" sudah selesai dibuat, mahasiswa diminta untuk dapat memainkan aransemen yang mereka buat. Proses ini berlangsung selama masa perkuliahan mata kuliah aransemen musik pendidikan II. Pada aransemen untuk combo band tidak terdapat kendala dalam memainkannya. Kendala terdapat pada saat memainkan instrumen rekorder. Sebagian besar mahasiswa belum menguasai alat rekorder, padahal instrumen rekorder digunakan dalam aransemen lagu tersebut. Mahasiswa memang dituntut untuk dapat memainkan setiap instrumen yang terdapat dalam aransemen, sehinga mereka dapat menguasai materi aransemen dan teknik permainannya serta mampu memberikan contoh bermain instrrumen secara langsung kepada para sisiwa di sekolah.

Proses awal pengajaran hasil aransmen dalam bentuk ansambel musik yaitu seluruh siswa yang mengikuti kegiatan ekstrakurikuler musik berkumpul bersamasama sekaligus dengan guru pengampu ekstrakulikuler musik di sekolah. Para guru yang mengampu ekstrakurikuler musik sejak awal memang dilibatkan dalam proses pengajaran ansambel musik. Hal tersebut bertujuan agar guru juga mendapat ilmu serta wawasan pengetahuan tentang tahapan danbentuk aransemen yang tepat bagi siswa di sekolah. Guru juga diharapkan dapat mengajar musik dalam bentuk ansambel kepada siswa di sekolah, sehingga pembuatan aransemen musik serta pengajaran musik ansambel bagi siswa-siswa sekolah dapat terus berlanjut setelah kegiatan pengajaran ansambel musik di sekolah oleh mahasiswa sudah selesai.

Selanjutnya mahasiswa-mahasiswa memberikan contoh dengan cara memainkan secara langsung lagu yang sudah mereka buat aransmennya sewaktu mengikuti kuliah aransemen musik pendidikan di kampus. Hal tersebut bertujuan unruk memberikan Ilustrasian keseluruhan kepada siswa-siswa dan guru tentang aransemen lagu yang akan dimainkan. Setelah itu para siswa diajak untuk bernyanyi bersama-sama agar mereka menegtahui bentuk musiknya dan urutan aransmennya yaitu intro, lagu, interlude, lagu dan terakhir koda.

Setelah itu dengan bantuan guru, para siswa dibagi ke dalam kelompokkelompok sesuai dengan instrumen yang akan mereka mainkan.Kelompok musik terdiri dari kelompok siswa pemain instrumen rekorder, kelompok sisiwa pemain instrumen pianika, kelompok sisiwa pemain instrumen biola, kelompok siswa pemain perkusi atau ritmis dan kelompok sisiwa pemain instrumen combo band yang terdiri dari gitar elektrik, bass elektrik, keyboard dan drumset. Masing-masing kelompok ini kemudian dilatih oleh mahasiswa dalam ruang yang berbeda sesuai dengan pembagian instrumen masing-masing.

Proses pengajaran aransemen musik dengan bentuk anasambel musik menggunakan notasi balok atau notasi musik. Awal pengajaran, para siswa mengalami kesulitan memainkan instrumen musik dengan membaca notasi musik. Untuk mengatasi hal tersebut, siswa diajarkan membaca notasi mu- 
sik dengan membaca satu persatu notasi musik sekaligus memainkan pada instrumen.

Para siswa diajarkan membaca notasi balok per nada satu-satu sampai mereka hafal, dimainkan dengan tempo lambat dan berulang-ulang. Itulah sebabnya mengapa nada yang digunakan pada instrumen rekorder dan pianika terbatas dalam wilayah nada satu oktaf dengan interval atau jarak nada yang tidak melompat atau jauh.

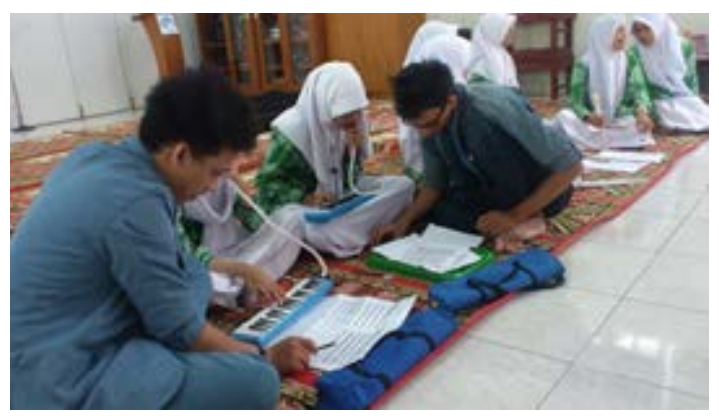

Ilustrasi 1.

Proses Pengajaran Aransemen Musik Siswa Kelompok Instrumen Pianika

Pada kelompok siswa instrumen musik biola, para siswa sebelumnya sudah mempunyai kemampuan bermain biola. Mereka pernah belajar les privat biola masing-masing dirumah. Hambatannya sama yaitu sebagian dari mereka sudah lupa cara membaca notasi musik dan letak penjarian tangan kiri. Mahasiswa akhirnya harus memberi contoh memainkan bagian aransemen untuk biola sehingga siswa dapat mendengarkan, membaca dan menghafalkan notasi balok serta letak penjarian pada instrumen biola.

Kelompok siswa instrumen perkusi memaikan alat-alat antara lain glokenspiel, tamborine, kastanyet, dan triangle. Kelompok sisiwa yang memainkan instru-men perkusi pada awalnya kesulitan membaca ritmis dengan pola-pola ketukan bervariasi dan pola ketukan sinkope. Pola-pola ketukan dengan variasi dan pola ketukan sinkope membuat siswa berkonsentrasi dalam memainkannya, Hal ini menjadi daya tarik dan tantangan tersendiri bagi kelompok sisiwa pemain instrumen perkusi untuk dapat memainkan pola-pola ritmis tersebut se-hingga mereka mampu memainkan dan menghafalkan pola ritmis dalam aransemen.

Kelompok siswa pemain istrumen combo band yang terdiri dari intrumen gitar elektrik, bass elektrik, keyboard dan drumset. Aransmen combo band untuk lagu "Dari Sabang Sampai Merauke" masih menggunakan akord-akord pokok dan tidak banyak menggunakan variasi akord.

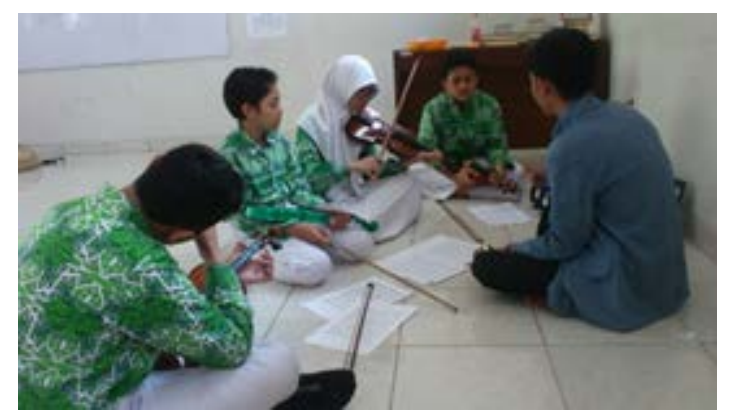

Ilustrasi 2.

Proses Pengajaran Aransemen Musik Siswa Kelompok Instrumen Biola

Para siswa pada kelompok combo band ini sebelumnya sudah terbiasa memainkan lagu-lagu popular yang mereka minati. Pada aransemen kali ini kelompok sisiwa combo band memainkan hasil aransemen dengan cara membaca lambang akord dan banyak melatih posisi-posisi penjarian akord pada instrumen gitar eletrik dan bas elektrik.

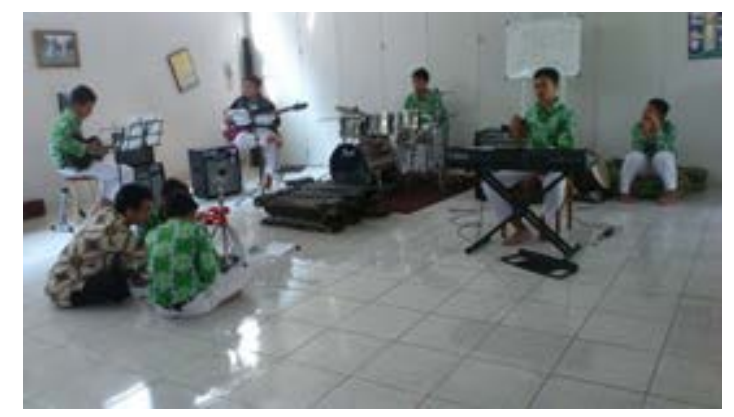

Ilustrasi 3.

Proses Pengajaran Aransemen Musik Siswa Kelompok Combo band

Siswa yang memainkan instrumen keyboard kebetulan sudah dapat membaca notasi musik, sehingga mahasiswa hanya 
melatih melancarkan membaca notasi dan memperbaiki posisi penjarian. Aransemen unruk instrumen drumset dibuat menggunakan pola rimis yang sederhana dan mudah. Siswa yang memainkan insrumen drumset mengalami sedikit kesulitan pada saat harus menyesuaikan pola ritmis atau ketukan dengan tempo lagu, sehingga terkadang tempo lagu menjadi turun atau terlambat, mahasiswa yang mendampingi harus memeberikan beat atau tempo di-sebelahnya sehingga tempo drum set tetap dapat terkendali.

Secara garis besar hasil aransemen mata kuliah aransemen musik pendidikan II dapat diplikasikan ke sekolah SMP Al Azhar Yogyakarta. Para sisiwa di sekolah selalu bersemangat pada saat pemgajaran ansambel musik oleh para mahasiswa. Kegiatan ekstrakurikuler musik biasanya ditampilkan di acara-acara sekolah Al-Azhar seperti Akhirusanah (tutup tahun), Syawalan, Parent Meeting, Open House, Semarak Muharam dan lain sebagainya Hasil pembelajaran Aransemen lagu "Dari Sabang Sampai Merauke" dipentaskan oleh siswa sekolah kelas VII dan VIII pada acara Akhirusanah atau tutup tahun Sekolah SMP Al Azhar pada bulan Juni di Auditorium MMTC Jalan Magelang Yogyakarta.

\section{Penutup}

Kesimpulan selama penelitian berlanjut, yaitu hasil aransemen mata kuliah aransemen musik pendidikan dapat di aplikasikan di SMP Al-Azhar. Bentuk aran-semen dengan format ansambel yang menggunakan instrumen rekorder, pianika, biola, glokenspiel, perkusi, gitar elektrik, bass elektrik, keyboard, drumset serta vokal menjadi ansambel musik bentuk baru yang memang tepat bagi kegiatan ansambel musik di Sekolah Menengah Pertama.

Saran bagi pengajaran mata kuliah aransemen musik anak adalah menentukan sekolah yang akan dijadikan tempat mahasiwa melakukan pengajaran ansambel musik sejak awal perkuliahan. Tujuannya agar dapat menyesuaikan jika ada masukan atau permintaan dari sekolah untuk mengaransemen lagu tertentu dari sekolah yang dipilh. Pada penelitian ini, sekolah SMP Al-Azhar meminta lagu tambahan lagu islami untuk dapat dipentaskan oleh sisiwasiswa pada saat acara perayaan keagamaan.

Tentang pelaksanaan pengajaran ansambel musik di sekolah oleh para mahasiswa, sebaiknya jadwal pengajaran ke sekolah durasi pertemuannya ditambah minimal menjadi delapan kali pertemuan, satu minggu satu kali pertemuan, Pengajaran hasil aransemen ke sekolah yang berlangsung selama ini dilakukan sebanyak 4 kali pertemuan, satu minggu 1 kali pertemuan. Durasi pertemuan selama 4 kali tersebut ternyata belum cukup bagi mahasiswa untuk memberikan materi secara menyeluruh, dan bagi para siswa di sekolah masih membutuhkan bimbingan untuk dapat menguasai materi yang diberikan secara menyeluruh.

\section{Referensi}

Christopher. 1980. Music-Society-Education. London: John Calder

Duckles, Vincent et al. 1980. "Musicology" dalam Stanley Sadie (ed.), The New Grove Dictionary of Musical Instruments and Musicians, Volume 12. London: Macmillan Publisher Limited

Fletcher, Peter. 1987. Education and Music. New York: Oxford University Press.

Haryadi, Frans dkk. 1976. Metode Pendidikan Musik Untuk Sekolah Dasar dan Sekolah Menengah Pertama. Jakarta: Depdikbud.

Hurlock, Elizabeth B. 1991. Perkembangan Anak (terj. Meitasari Tjandrasa),. Jakarta: Airlangga 
Kawakami, Genichi. 1975. Arranging Popular Music: A Practical Guide. Tokyo-Japan: Yamaha Music Foundation.

Meleong, Lexy J. 2004. Metodologi Penelitian Kualitatif. Bandung: PT Remaja Rosdakarya

Miller, Hugh M. 1971. Introduction to Music, A Guide to Good Listening. New York: Barnes \& Nobles Inc.

Newman, Grant. 1979. Teaching Children Music, Fundamental of Music and Methode. USA: Wim C. Brown Publisher.

Sadie, Stanley (ed.). 1980. The New Grove Dictionary Music and Musicians. London: Macmillan Publisher Ltd.
Scholes, Percy A. 1978. The Oxford Companion to Music. London: Oxford University Press.

Soedarsono, R.M. 2001. Metodologi Seni Pertunjukkan dan Seni Rupa. Bandung: Masyarakat Seni Pertunjukan Indonesia.

Stein, Leon. 1979. Structure and Style: The Study and Analysis of Musical Form, Expand Edition. New Jersey, USA: Summy - Birchard Music.

Strube, Gustav. 1978. The Theory and Use Chords, A Text-Book of Harmony. Philadelphia-USA: Oliver Ditson Company

Watanabe, Ruth T. 1976. Introduction To Music Research. New Jersey: PrenticeHall Inc. 